\title{
Mirada en perspectiva de la maternidad no planeada en egresadas de psicología de una universidad pública
}

Gloria Ángela Domínguez Aguirre, ${ }^{1}$ Adriana Martínez Peralta, ${ }^{1}$ Patricia Carrera Fernández ${ }^{1}$ y Claudia Soledad de la Fuente Pérez ${ }^{1}$

\section{Introducción}

La maternidad tiene significados diferentes para cada mujer, dependiendo de sus circunstancias y sus vivencias particulares. Intervienen variables como la personalidad, su historia infantil, edad, relación afectiva con el padre del bebé, características de su familia de origen, red de apoyo, situación económica y cuestiones culturales. Puede ser aliciente u obstáculo en su proyecto de vida con el reto de conciliar los roles de estudiante y madre, respondiendo a las exigencias de la carrera con las expectativas personales y sociales ligadas a la maternidad.

Testimonios de madres adolescentes mexicanas que reflejan angustia ante la perspectiva de ser responsables de la vida de otra persona cuando aún no cuentan con estrategias para afrontar la propia son referidos por García, Acuña y Preciado (2005). Serrano y Sánchez (2000) abordan la paradoja entre dos nociones de sujeto: ser estudiante, y por ende, sujeto en forma-

1. Universidad Juárez Autónoma de Tabasco. 
ción, dependiente e "incompleto", y ser madre y, por ello, responder por otra persona suministrándole las condiciones afectivas y efectivas para su existencia.

Nóblega (2009) identifica tres significados de la maternidad en mujeres peruanas que fueron madres adolescentes:

a) La maternidad como referente de la definición de sí misma. Estas mujeres ya no esperan un futuro, tienen un presente en el que la maternidad es parte de su autoconcepto.

b) La maternidad como una oportunidad de cambio. Significa una responsabilidad y también representa un cambio positivo mediante el cual se puede adquirir la madurez, de modo que el hijo o hija se convierte en un regulador de la conducta de la madre, que le genera mayor conciencia de sus actos.

c) La maternidad como una fuente de afecto. La maternidad posiblemente se sobrevalora por la situación de soledad en que las mujeres se perciben a sí mismas, lo cual puede ser una causa del embarazo no deseado. En tal caso, el hijo o hija adquiere importancia por ser percibido como algo propio, en medio de carencias afectivas.

\section{Método}

Participantes

Ocho mujeres egresadas de la licenciatura en Psicología de una universidad pública.

Material

Guía de preguntas para el grupo focal, grabadoras reporteras, cédula de identificación y material humano (dos docentes, dos estudiantes tesistas). 


\section{Procedimiento}

Estudio cualitativo y transversal, utilizando la técnica de grupo focal. Las categorías y códigos de estudio fueron: Proyecto de vida: anterior a la maternidad y cambios generados en el mismo; Embarazo: primeras reacciones y/o vivencia del mismo, y Maternaje: emociones y pensamiento sobre el inicio de la maternidad y modificación del concepto de "madre". El texto producto de la transcripción de la grabación se revisó mediante el análisis de contenido inductivo.

\section{Resultados}

Las participantes tienen entre 23 y 31 años; seis están tituladas y dos son pasantes. Cuatro están casadas o viviendo con el papá de sus hijos, tres son solteras y una divorciada. Estas últimas cuatro viven con sus hijos, en la casa de su familia de origen, tres de ellas trabajan, dos se encuentran estudiando (una maestría y otra una segunda carrera), y tres se dedican al hogar. Seis refieren que sus embarazos no fueron planeados y dos enfrentaron diagnósticos de infertilidad, buscado un embarazo previamente, pero al momento de darse no lo habían planeado.

Respecto al proyecto de vida prematernal hay alusiones a planes académicos y personales en todas las participantes, refiriendo el matrimonio y la maternidad a largo plazo:

"(Casarme) era muy lejano. Yo pretendía primero vivir sola y terminar la carrera, trabajar y luego casarme. Ése era mi superproyectazo de vida" (R., 27 años, hija de 5).

"Estaba planeando irme de intercambio y poder seguir en mis clases de danza" (R., 23 años, hija de 2).

"Estaba haciendo los trámites para estudiar una maestría en España" (L., 31 años, hijo de 5).

Para Neyman (1999) el cuidado de un niño o niña es considerado un trabajo de tiempo completo y puede ser muy estresante para la estudiante universitaria si el embarazo incluso ha sido planeado. La crianza consume tiempo y energía. En solita- 
rio o en pareja, la elección de criar puede ser gratificante aun si la tarea es desalentadora financieramente.

En los cambios generados en el proyecto de vida, se distinguen dos elementos importantes: 1 ) dificultades para organizar su tiempo en función de la maternidad y otras actividades, y 2) duelo o sensación de pérdida por aquellos planes abandonados:

"Aún sigo organizando, después de cuatro años [sic]. Ya no tan fácilmente puedo lanzarme a lo que quiero, siempre hay un tope, siempre tengo como prioridad atenderlo a él. Aún no encuentro esa cuadratura de lo que quiero y cómo atender a mi hijo sin que un tercero intervenga" (L., 31 años, hijo de 5 años).

"Mi plan a corto plazo se derrumbó, mis clases de danza, que era lo que más amaba, mi pasión" (R., 23 años, hija de 2 años).

"Desde la secundaria se me metió la idea de que quería vivir sola y eso fue lo que ya no hice". "Hasta la fecha no logro el equilibrio, la culpa está latente. Me voy a trabajar y mi hija está durmiendo, regreso y ya se fue a dormir, o peor, noto que se esmera por levantarse temprano, aunque se esté cayendo de sueño, quiere estar conmigo y eso me pega horriblemente" (R., 27 años, hija de 5 años).

"No me preocupaba tanto por la escuela, porque ya había terminado, sino por cómo iba a mantener un hijo, porque no estábamos estables económicamente mi esposo y yo" (S., 25 años, hijo de 2 años).

Para Oiberman (2004), ser madre en la especie humana excede el hecho biológico y tiene un significado a nivel social, cultural, histórico y psicológico. De tal forma, el maternaje puede ser definido como el conjunto de procesos psicoafectivos que se desarrollan e integran en la mujer en ocasión de su maternidad.

Así surge la tercera categoría: maternaje, que se analiza con los códigos de emociones y pensamiento sobre el inicio de la maternidad y modificación del concepto de "madre".

Sobre la vivencia del embarazo, las chicas refirieron síntomas fisiológicos propios de la gestación, añadiendo tristeza, soledad, sensación de abandono por su familia y falta de apoyo de las parejas, en la parte emocional: 
"Creo que lo fisiológico afecta bastante porque a mí me daba mucho asco el papá de mi hija, mucho asco su olor, se cambió tres veces de perfume, no toleraba verlo, no me gustaba su olor" (R., 23 años, hija de 2).

Aun habiendo asumido el embarazo gustosamente, sin acompañamiento de la pareja, se pueden vivir momentos de depresión al ubicarse en un contexto social en el que sí la hay:

"Cuando ves que te crece la panza y miras para todos lados y hay parejas disfrutando la pancita y todo, y tú vas caminando sola... eso me empezó a deprimir mucho, mucho, yo creo que también las hormonas le juegan chueco a una" (L., 31 años, hijo de 5).

Sobre las emociones y pensamientos surgidos al ser madres, las participantes relatan experiencias intensas:

"Lloré de felicidad, no paraba de verlo, acariciaba sus mejillas, fue una sensación muy bonita, jmuy emocionante!" (P., 24 años, hijo de 4).

"[...] esa emoción que te da cuando (lo) ves por primera vez, se te cierra la garganta, se te nubla la vista y cosquilleo hasta en el cerebro sientes; no sé de dónde sale todo, pero se siente muy padre, como que se atonta una" (R., 23 años, hija de 2).

Sin embargo, el maternaje modifica el concepto de ser madre:

"Yo pensaba que era una felicidad eterna y perpetua, que nunca iba a ser infeliz, yo creo que uno es la mejor mamá hasta que le toca ser mamá [...] Soy descuidada, se me olvidan las vacunas, se me olvida mi hija en la guardería [...] enfrentarte a las situaciones económicas, a los tiempos [...] va menguando un poco la felicidad" (R., 27 años, hija de 5).

"Yo pensaba que la maternidad iba a ser muy fácil y muy bella todo el tiempo [...] la realidad es que tienes que empezar a ser responsable con las enfermedades, con cosas [...] en ese momento cambia la perspectiva: 'a ver, espérate, ya no eres tú sola por la vida quedándote sin un solo peso al final de la quincena sino que ahora tienes que administrarte', realmente a mi hijo le debo el ser medio organizada, mis tiempos, mi economía y creo que me dio estabilidad en general en mi vida" (L., 31 años, hijo de 5).

Preciado, Acuña, García y Kral (2011) encontraron como tema central la percepción de la maternidad como etapa de cam- 
bio y crecimiento proveyendo identidad y nuevas responsabilidades, dado que tienen que ajustarse al cumplimiento de dos o tres roles más: madre, esposa, compañera y probablemente trabajadora asalariada, generándoles esto repercusiones en su desempeño académico. De tal suerte que la maternidad tiene un efecto estabilizador por ser considerada un impulso que incrementa la determinación y motivación para lograr sus aspiraciones (Camarena, Minor, Melmer y Ferrie, 1998).

\section{Conclusiones}

Mirando retrospectivamente la maternidad de las participantes se concluye que el proyecto de vida inicial requirió modificación a partir del embarazo, dejando algunos planes truncos, con consecuente sensación de pérdida, tanto si se vivió en pareja o en solitario. Aunque la experiencia fue intensa e incluso dolorosa, la maternidad trajo consigo felicidad, resignificando el concepto de madre cotidianamente y propiciando una perspectiva con mayor identificación. 


\section{Referencias}

Camarena, P., Minor, K., Melmer, T. y Ferrie, C. (1998). The nature and support of adolescent mothers' life aspirations. Family Relations, 47(2). 129-137. Recuperado de http://www. jstor.org/.

García, M.E., Acuña, M.E. y Preciado, F. (2005). Repercusiones del embarazo y la maternidad en la vida académica de las estudiantes universitarias. Biblioteca virtual de la Universidad de Colima, 13(36), 125-132. Recuperado de http:// bvirtual.ucol.mx.

Neyman, J. (1999). One pregnancy = difficult decisions. California Intercollegiate Press Association. Recuperado de http://www.laverne.edu/ctimes/bestoct/neyman00.htm.

Nóblega, M. (2009) La maternidad en la vida de las adolescentes: implicancias para la acción. Revista de Psicología 27(1), 29-54. Recuperado de http://revistas.pucp.edu.pe.

Oiberman, A. (2004). Historia de las madres en occidente: Repensar la maternidad. Revista Psicodebate Psicología, Cultura y Sociedad. 5, 115-129. Recuperado de http:// www.palermo.edu/cienciassociales/investigacion-y-publicaciones/revista-psicodebate/.

Preciado, F., Acuña, M.E, García, M.E y Kral, K. (2011). Un acercamiento a la situación de gestación, maternidad y paternidad en el estudiantado (19-25). En Preciado, F. et al., La influencia del género en la vida académica de estudiantes de educación superior gestantes, madres y padres. Colima: Universidad de Colima.

Serrano, R. y Sánchez, B. (2000). Subjetividad materna y paterna adolescente y juvenil. Revista Nómadas. 13. 265-267. Recuperado de http://www.redalyc.org. 